\title{
Resiliência social na Floresta Atlântica do Rio Grande do Sul: 0 uso dos sistemas ecológicos na produção de banana
}

\begin{abstract}
Resumo
A utilização dos recursos da Floresta Atlântica, Patrimônio Nacional, tem sido restringida pela legislação ambiental, por meio do Código Florestal Brasileiro (Lei no 1.428/2006), do Código Florestal Estadual (Lei no 9.519/1992) e do Código Estadual do Meio Ambiente (11.520/2000). Diante disso, o objetivo deste estudo é avaliar a capacidade de resiliência social ecológica dos moradores da microrregião do Litoral Norte, no Rio Grande do Sul, que obtinham seu sustento da agricultura, com sistemas produtivos baseados na queimada, e viram esse sistema comprometido, restando-Ihes poucas alternativas, entre elas, o abandono das áreas. O estudo analisa, através de 53 entrevistas, os recursos e relações locais utilizados pelos habitantes, além de alguns indicadores socioeconômicos, como o Índice de Desenvolvimento Humano (IDH), a Superfície Agrícola Útil (SAU) e o Produto Bruto (PB) para verificar as transformações locais. O artigo demonstra que recursos e relações locais foram fundamentais para ajudar as comunidades a lidar com os impactos da nova Legislação Ambiental imposta nos seus espaços de vida e produção. Também como os sistemas (SAF) permitem a produção agrícola com a conservação e o uso sustentável das florestas, configurando-se isso nas respostas de quase 500 bananicultores, ao permitir o uso da terra e a melhora na renda dos produtores.
\end{abstract}

Palavras-chave: Resiliência Social. Sistemas Agroflorestais. Mata Atlântica. Rio Grande do Sul.

\begin{abstract}
The use of resources of the Atlantic Forest, National Heritage, has been restricted by environmental legislation, through the Brazilian Forest Code (Law no 1.428/2006), the State Forest Code (Law 9,519 / 1992) and the State Environmental Code (11,520/2000). Thus, the aim of this study is to evaluate the ecological social resilience of the residents of micro North Coast, Rio Grande do Sul. What they obtained their living from agriculture, with production systems based on fire, and saw this compromised system, leaving few alternatives, including the abandonment of areas. The study analyzes through 53 interviews, local resources and relationships used by the inhabitants, and some socio- economic indicators, such as the Human Development Index (HDI), the utilized agricultural area (UAA) and the crude product (PB) to check local transformations. The article demonstrates that local resources and relationships were essential to help communities cope with

\footnotetext{
${ }^{1}$ Geógrafa, mestre e doutora em Desenvolvimento Rural. Pós-Doutoranda no Programa de PósGraduação em Desenvolvimento Rural.garcezd@gmail.com

${ }^{2}$ Cientista Social, mestre em Sociologia e doutora em Desenvolvimento Rural. carolinabcs@yahoo.com.br

${ }^{3}$ Médico Veterinário, mestre em Economia Rural e doutor em Economia Agroalimentar. Professor no PGDR-UFRGS. joao.dessimon@ufrgs.br
} 
the impacts of new environmental legislation imposed in their living spaces and production. Also how systems (SAF) allow agricultural production to conservation and sustainable use of forests, setting up in nearly 500 banana growers response, by allowing the use of land and improve the income of producers.

Keywords: Social Resilience. Agroforestry Sistems. Atlantic Forest. Rio Grande do Sul.

\section{Introdução}

A região de encosta Atlântica do litoral do Rio Grande do Sul é considerada um limite austral da floresta ombrófila densa (Floresta Atlântica) no Brasil e tem sido cada vez mais visada pela legislação com fins de conservação ambiental. Nas últimas duas décadas, a partir de 1992, houve um crescente aprofundamento nas restrições de atividades produtivas nas áreas de floresta. Neste mesmo ano, começou, no Rio Grande do Sul, a regulamentação de atividades produtivas por meio da implementação de legislações que tinham por principal objetivo a conservação das áreas de Floresta Atlântica.

Atualmente, estima-se que a área remanescente da cobertura original da Floresta Atlântica seja em torno de 5 a 7\%. Nestes espaços remanescentes, embora pequenos, abrigam-se uma das mais altas taxas de biodiversidade do planeta, registrando aproximadamente 20.000 espécies vegetais e 1.650 animais, sendo que 8.000 são espécies endêmicas, ou seja, somente ocorrem nestes ambientes (PEROTTO, 2007).

Estimativas sobre o Rio Grande do Sul apontam que, no início do século vinte, havia $133.370 \mathrm{Km}^{2}$ (49,55 \% do território gaúcho) de áreas pertencentes ao Domínio Mata Atlântica. Atualmente, entretanto, segundo Perotto, (2007), restam apenas $21.299 \mathrm{Km}^{2}$ com presença de vegetação nativa, o que equivale a aproximadamente $16 \%$ deste polígono e apenas 7,91 \% do RS. Como ressalta o autor (2007), a biota existente neste bioma contribui para ajustar o clima, a temperatura, a umidade e as chuvas, beneficiando 120 milhões de brasileiros que nela residem. Influenciam também a fertilidade do solo, o qual protege escarpas de serras e protege nascentes, contribuindo de forma direta para a manutenção e existência dos fluxos dos mananciais de água, que abastecem cidades e comunidades do interior.

Seguindo tendências mundiais de conservação e proteção dos recursos naturais, especialmente a partir do final dos anos de 1980 e particularmente a partir dos anos 1990, diversos esforços foram despendidos, objetivando definir estratégias e políticas para a conservação do bioma da Floresta Atlântica e ecossistemas associados no Brasil (PEROTTO, 2007). O tombamento da Mata Atlântica como Reserva da Biosfera representou um instrumento jurídico e administrativo que influenciou políticas públicas, com o objetivo de manutenção da diversidade biológica dos fragmentos remanescentes de vegetação nativa deste bioma ameaçado. Ela foi reconhecida pela Organização das Nações Unidas para a Educação, a Ciência e a Cultura (UNESCO) como Reserva da Biosfera e transformada em Patrimônio Nacional pela Constituição Federal Brasileira de 1988. Devido ao reconhecimento desse valor, houve uma ampliação nas restrições de possibilidades de sua utilização como um todo. Como instrumentos legais, podemos citar o Código Florestal Brasileiro, na Lei no 11.428 de 2006 (BRASIL, 2009b), o qual dispõe sobre a conservação, a proteção, a regeneração e a utilização da vegetação nativa. Também se 
pode citar a legislação estadual, ainda mais restritiva na utilização humana do bioma, através da Lei no 11.520/2000, que instituiu o Código Estadual do Meio Ambiente, e da Lei no 9.519/1992, que instituiu o Código Florestal Estadual (BRASIL, 2009a).

No Rio Grande do Sul, as restrições impostas no código Florestal de 1992 atuam fundamentalmente proibindo ações de corte, queima e exploração da vegetação nativa, impondo máximo respeito à fauna silvestre, permitindo atividades ligadas ao ecoturismo, à pesquisa científica e à educação ambiental (PEROTTO, 2007). A partir deste momento, com a vigência dessas ferramentas jurídicas, gerou-se um descompasso entre as ações de conservação e proteção impostas pela legislação e as formas de reprodução social das populações locais destas áreas.

Tradicionalmente, os moradores da microrregião do Litoral Norte, no Rio Grande do Sul, obtêm seu sustento da agricultura, geralmente em propriedades pequenas, com cerca de cinco hectares, com sistemas produtivos baseados na queimada e no uso de insumos de origem fóssil. A implantação da nova legislação comprometeu seu modo de produção, restando poucas alternativas, entre elas o abandono das áreas (WIVES, 2008). Assim, estas comunidades cujas áreas produtivas foram afetadas em alguma medida se defrontaram com um novo desafio e buscaram formas de manter sua reprodução social.

Diante desse contexto, este estudo busca desvelar como tais comunidades encontraram novas formas de organização e interação com o ambiente, resistindo a esse novo cenário, que alterou toda sua organização produtiva, através da produção ecológica nos moldes dos sistemas agroflorestais. Dessa forma, como resiliência social, neste estudo, considera-se a capacidade que um sistema social tem para absorver processos de autodesenvolvimento, tendo condições não só de resistir à adversidade, mas de utilizá-la em seu processo de desenvolvimento social inter-relacionado ao ecossistema (SORIA, BLANDTT; RIBEIRO, 2007). O conceito de resiliência vem evoluindo ao longo do tempo: inicialmente, foi concebido apenas como capacidade ou potencial de adaptação e regeneração, ou seja, a capacidade de ajuste a um ambiente desajustado.

O conceito empregado neste estudo foi definido por Soria, Blandtt e Ribeiro, (2007). Conforme estes autores, a resiliência social-ecologia sistêmica é entendida como a capacidade que um sistema social tem para poder absorver processos de autodesenvolvimento, tendo condições não só de resistir à adversidade, mas de utilizá-la em seu processo de desenvolvimento social correlacionado com o ecossistema. Os autores (2007, p. 6) argumentam que:

Baseado em Glaser et al. (2005), a resiliência social-ecologia é compreendida como a capacidade dos sistemas sociais para a auto-organização adaptando-se e desenvolvendo-se diante dos choques ou com a integração a mudanças no seu cotidiano mantendo as funções do sistema da sociedade e do meio ambiente. [...] A resiliência social-ecologia é, entretanto, altamente dependente das características econômicas, sociais e culturais da sociedade em questão. Isto implica que o conhecimento que os usuários do sistema possuem de sistemas de valores, da cultura e das estruturas econômicas é crucial para a definição e capacitação da resiliência social-ecologia e, em conseqüência, também para o planejamento de formas de organização do manejo participativo no meio ambiente. 
Assim, o processo de resiliência estaria mais associado a indivíduos e comunidades rurais pobres, onde há, necessariamente, um estado de vinculação produtiva, cultural e social aos recursos naturais (SORIA; BLANDTT; RIBEIRO, 2007). Em geral, são populações que se encontrem em circunstâncias notadamente complexas, em relação ao ambiente. Salienta-se que é chave a forma como essas populações encaram tais dificuldades e as percebem como oportunidades de mudança. Assim, desenvolvendo a disposição de perceber esses processos complexos e, por muitas vezes, restritivos em relação ao ambiente, como uma força de transformação e construção social positiva.

O cultivo da banana configura-se como uma das produções de maior expressão comercial da porção atlântico sul da floresta, apresentando dois sistemas de cultivo distintos: um utilizando técnicas de manejo convencionais, e outro, antagônico, de base ecológica.

Sob a ótica do desenvolvimento rural sustentável, tecnologias de manejo dos sistemas agroflorestais (SAF) aproveitam os princípios ecológicos de produção, gerando sistemas mais produtivos e de menor impacto ambiental. Eles associam diversos tipos de manejos, tais como rotação de cultivos, controle biológico, cultivos associados, sistemas mistos agropecuários, insumos alternativos, entre outros.

Na microrregião do litoral norte do RS, em torno de 500 agricultores dedicamse à produção ecológica, usando os sistemas agroflorestais (SAF). A singularidade dos sistemas SAF vem configurando-se como uma resposta à situação enfrentada no litoral norte, cujo principal expoente é a bananicultura. Isto se dá, sobretudo, pelo trabalho desenhado, inicialmente, pelo Centro Ecológico Ipê Serra - Litoral Norte - Assessoria e Formação em Agricultura Ecológica (CE), localizado desde 1991 no município de Dom Pedro de Alcântara.

A mudança do modelo convencional para SAF vem alterando a geografia da produção e proporcionando uma reorganização total do modelo produtivo e de organização dessas comunidades. O SAF, para esses agricultores que se organizaram e se associaram, representou uma alteração profunda no sistema social no qual estavam inseridos. $O$ uso do SAF representou, através de suas práticas, diversas formas de representações socioambientais, das técnicas, da exploração dos recursos, da organização e gestão dos territórios, uma nova forma de relação dos agricultores com os recursos naturais.

\section{Métodos utilizados}

A área delimitada, para realizar este estudo, localiza-se na Microrregião de Osório, Rio Grande do Sul. Do total da microrregião, foram selecionados cinco municípios, devido à sua representatividade no cultivo da banana: Torres, Mampituba, Dom Pedro de Alcântara, Morrinhos do Sul e Três Cachoeiras.

O processo de seleção da amostra iniciou com a definição da população a ser estudada, a qual foi composta por produtores de banana de base ecológica. Estima-se que haja em torno de 450 a 500 agricultores dedicados ao cultivo de banana de base ecológica em toda a Microrregião do Litoral Norte, gerando-se uma amostra de 53 agricultores, representando pouco mais de $10 \%$ da população total estudada. 
Partindo-se de um viés quantitativo, foi elaborado um questionário fechado, ou seja, no qual as questões e possíveis respostas são pré-formuladas, conforme os interesses da pesquisa. Esse tipo de questionário torna-se útil na medida em que otimiza os recursos financeiros e o tempo necessários para a coleta de dados. Assim, no decorrer do período de pesquisa de campo, compreendido entre os meses de fevereiro até agosto de 2012, em diversas visitas à região, foram aplicados questionários fechados para os 53 agricultores, compondo o tamanho de amostra mínimo esperado para uma população estimada em cerca de 500 agricultores.

Neste trabalho, são analisados alguns indicadores sociais e econômicos, para compreender os recursos e relações locais utilizados pelos habitantes frente à nova legislação, mais restritiva. No campo dos indicadores econômicos, foram utilizados a Superfície Total, a Superfície Agrícola Útil (SAU), o Produto Bruto (PB), e a Unidade TrabaIho Homem (UTH), além do Índice de Desenvolvimento Humano (IDH), como indicador social.

Saber a Superfície Total, em hectares, fornece um importante dado a respeito da quantidade de terra disponível aos agricultores. No entanto, é através da SAU que se obtém a área, em hectares, que de fato é utilizada para cultivo, descartando-se áreas não cultivadas e de preservação. Também não são contabilizadas áreas não exploradas, como as ocupadas pelas construções, horta e pomar domésticos ou de reflorestamento.

O cálculo do Produto Bruto revela o valor, em reais, do que foi produzido durante o ano pela unidade de produção. Para esta avaliação, utilizam-se os valores de produção final vendida, consumida, transformada e estocada pela família, bem como a produção utilizada para pagamento de serviços a terceiros, a variação do rebanho animal e a remuneração de serviços prestados para terceiros pela mão de obra familiar.

Já a medida da UTH refere-se à quantidade de tempo trabalhada por unidade de mão de obra. Para se chegar ao valor final, é estabelecido o valor de 300 dias-homem ou 2.400 horas de trabalho ao ano, o qual equivale a 01 UTH para homens entre 16 e 60 anos, integralmente ocupados na propriedade familiar. Para mulheres de mesma idade e com a mesma quantidade de trabalho, o valor é de 0,8 , enquanto crianças e adolescentes abaixo de 16 anos e idosos acima dos 60 anos recebem o valor 0,5.

Além disso, utilizou-se como indicador social o IDH, medida sintética do desenvolvimento de países, estados ou municípios. Neste caso, utilizam-se os valores municipais fornecidos pelo Programa das Nações Unidas para o Desenvolvimento (PNUD, 2013) e calculados a partir do Censo Demográfico, utilizando critérios de renda, longevidade e educação. O critério de resiliência social, no âmbito ambiental, serviu para avaliar a repercussão nas decisões de manejo de ecossistema na estabilidade institucional em nível comunitário e das sociedades.

\section{Os produtores agroecológicos da Floresta Atlântica do sul do Brasil}

Em meio a esse processo de modificação social das funções dessas unidades de paisagem, veio a se somar, também, no início desta década, a crescente implantação das leis de preservação ambiental e o seu efetivo controle pelos órgãos de fiscalização. 
A legislação ambiental implica algumas restrições de uso das áreas para os plantios temporários. Porém, como a banana é um cultivo permanente, as áreas que já estavam estabelecidas não sofreram impactos, ficando a medida restrita à ampliação das plantações.

Nesse sentido, municípios como Mampituba viram comprometida grande parte das suas áreas ocupadas com cultivos temporários, bem como restringida a produção dos derivados de cana-de-açúcar pelas regulamentações de instrumentos legais, de forma que o cultivo da banana passou a ser uma opção viável, já que, uma vez ocupadas as áreas de cultivo, elas podem ser consideradas como permanentes. Assim, muitos agricultores ocuparam suas roças, antes de se tornarem capoeiras, com bananais. Em Mampituba, de acordo com o com as palavras do senhor Tiriva:

[...] a banana passou a ser uma solução para que não se perdesse as áreas de plantio e trocar a cana. A cana dava muito trabalho, era coisa pesada. E, depois, ainda tinha que levar pra fazer açúcar, e puxa-puxa e cachaça e daí vender. A banana nem dá quase sofrimento, é coisa certa. Paga pouco, mas é certo, melhor que a cana, é nosso ouro verde. Agora todo mundo tá na planta da banana (ENTREVISTA, 2012).

Conforme já havia ocorrido a partir dos anos de 1950, quando se iniciou a produção da banana, com as novas legislações, os produtores que tinham suas áreas de encostas com elevada declividade, cobertas com florestas, não podiam mais desmatá-las. Por outro lado, a banana é uma planta considerada como espécie de cultivo permanente, com baixo aporte de mão de obra, e que pode ser cultivada em terrenos mais acidentados, adequando-se perfeitamente às características das unidades produtivas dessas UP's.

A banana é cultivada em uma faixa altimétrica de, no máximo, 400 metros, pois esse é o limiar para este cultivo, seja pelo frio, geada ou condições para realizar o manejo das plantações.

Nessas unidades de paisagens de alta, média e baixa encosta, a bananeira tem as melhores condições do estado para se desenvolver, pois se trata de uma planta que exige calor, precipitações bem distribuídas ao longo do ano e elevada umidade para o seu bom desenvolvimento e produção, condições que são propiciadas pelos microclimas nas escarpas e fundos dos vales.

Nessas condições paisagísticas, evidenciam-se indicativos que demonstram porque o sistema de cultivo ecológico SAF se relaciona de forma mais harmoniosa com as potencialidades deste espaço.

O SAF é utilizado nos sistemas ecológicos apresentando um nível de tecnificação baixo em relação a equipamentos de tração, por exemplo. Há uso de pulverizadores manuais, na maioria dos casos, além de tração animal e motriz leve, para recolher a colheita e auxiliar na adubação, como demonstra a Tabela 1: 
Tabela 1 - Sistema de cultivo SAF - principais características

\begin{tabular}{|c|c|}
\hline Indicadores & Características \\
\hline Nível de mecanização & Baixo \\
\hline Tração & Basicamente animal \\
\hline Sanidade & $\begin{array}{l}\text { Uso de óleo mineral, biofertilizantes, controle } \\
\text { biológico e controle da insolação }\end{array}$ \\
\hline Adubação & $\begin{array}{l}\text { Manual, cama de peru, cama de frango, cama de } \\
\text { gado, adubo verde, calcário, fosfato natural, pó de } \\
\text { rocha, pó de casca de arroz }\end{array}$ \\
\hline Pulverização & Pulverizadores manuais \\
\hline Cobertura do solo & Cobertura total com alto teor de biomassa \\
\hline Colheita & Manual \\
\hline Tempo de formação dos cachos & 7 meses \\
\hline $\begin{array}{l}\text { Problemas } \\
\text { de efeitos } \\
\text { naturais }\end{array}$ & $\begin{array}{l}\text { Sim, realiza-se um controle do sombreamento das } \\
\text { árvores que compõem o SAF de modo que favoreça } \\
\text { a produção }\end{array}$ \\
\hline Frio e ventos & Sim, quebra-vento \\
\hline
\end{tabular}

Fonte: Wives (2008).

Neste sistema de cultivo, tratos como a roçagem são seletivos. Por um lado, ela maneja a sucessão natural do sistema, e, por outro, o excesso de luminosidade, bem como a menor fertilidade, por meio da observação do maior crescimento de plantas, como o picão preto.

É necessário ressaltar que cada agricultor utiliza espécies vegetais que já existem em sua propriedade, ou insere outras diferentes, além dos bananais. Como árvores que compõem o sistema, pode-se citar a capororoca (Rapania umbellata), a aroeira vermelha (Schinus terebentifolia), as canelas em geral (Lauraceae), os ingás (Inga spp., Leguminosae-Papilionoideae), o louro (Cordia trichotona), o palmiteiro (Euterpe edulis), entre outras.

As plantas são podadas, em geral, anualmente, para não sombrear demais o bananal, e seus galhos e folhas são espalhados entre as bananeiras. A fertilização é alcançada com a decomposição da biomassa gerada pelas podas, à qual é acrescida também a cama de frango, peru ou gado, o calcário de conchas e o fosfato natural de rochas. Os agricultores também utilizam o chamado adubo verde, composto pelo material das roçadas, desbrotes, folhas e talos das bananeiras. Em alguns casos, verificou-se também o aporte de boro e de zinco.

É importante ressaltar que, neste sistema, não se fazem capinas, pois estas retiram totalmente a cobertura do solo; sendo, portanto, realizada somente a roçada, que apenas controla a cobertura vegetal. Isso explica o alto índice de cobertura do solo deste sistema. Os agricultores realizam a limpeza com o objetivo de fertilização do solo e tam- 
bém para possibilitar o trânsito de luz e de ar no bananal e ainda auxiliar na prevenção de doenças.

A sanidade dos bananais, neste sistema de cultivo, está fundada em tratos que vão desde a limpeza (roçadas) até a pulverização de óleo mineral e de biofertilizante, sendo realizada basicamente nos meses de novembro a março. A determinação da coIheita exige que os produtores estejam sempre atentos à observação do calibre e idade do cacho, atividade que é desenvolvida o ano todo. $O$ corte é realizado manualmente.

Os problemas de cunho natural, como a incidência de radiação, na forma de luz e calor, buscam ser compensados pelas técnicas do SAF. Também são empregados quebra-ventos, para controlar ou amenizar os efeitos dos ventos e do frio, igualmente identificados como sendo fatores de interferência na atividade deste sistema de cultivo.

Após a inflorescência, o tempo médio de formação dos cachos, neste sistema, é de sete meses. O sistema apresenta, assim, o ciclo mais longo dentre todos os demais, pois uma das suas premissas consiste em manter o respeito pelos processos ecológicos, não forçando, ou induzindo um amadurecimento precoce por meio da artificialização.

O SAF é empregado pelos agricultores buscando preços e comercialização diferenciados (sem atravessadores), aumento da qualidade e custo de produção diferenciado, de forma que os produtores se organizaram em associações para realizar o comércio.

Atualmente vendem sua produção em quatro feiras ecológicas, diretamente para o consumidor. Fundamentalmente, a criação e inserção em novos mercados se deu graças a sua capacidade de organização local e à pressão sobre as instituições públicas e privadas, gerando esses espaços diferenciados de comercialização, mudando a matriz de sua inserção social. Assim, esses alimentos locais expõem muito mais do que o produto orgânico (limpo, artesanal), ilustram uma forma de defesa da autonomia dessas comunidades. Dessa forma, os dados expostos a seguir demonstram, para além da quantidade da área que efetivamente estes têm para produzir, a forma como tiveram que articular todos os seus saberes novos, tradicionais e imersos na riqueza paisagística da floresta para continuar e se manter em suas comunidades.

\section{Os produtores do ouro verde}

Esta seção apresenta algumas características socioeconômicas da amostra de produtores utilizada nesta pesquisa. Em primeiro lugar, empregando algumas técnicas de estatística descritiva, foi realizada uma caracterização do perfil dos produtores, a qual foi construída por meio da descrição socioeconômica e da estrutura fundiária das propriedades, caracterizando o ambiente interno. Tais características encontram-se resumidas a seguir.

A Tabela 2 demonstra as médias das idades dos casais de agricultores compreendidos na amostra. A média de idade para os agricultores chefes da propriedade é de 48 anos, enquanto a de seus cônjuges é de 46 . No entanto, destaca-se que esses casais estão na faixa etária de 27 a 67 anos, indicando tanto casais de jovens quanto de pessoas com idade mais avançada. 
Tabela 2 - Idade dos produtores

\begin{tabular}{lccccc}
\hline Casal & Quantidade & Média & Desvio Padrão & Val. Mín. & Val. Max \\
\hline Agricultor & 53 & 48,77 & 9,30 & 29 & 67 \\
Cônjuge & 47 & 46,36 & 9,30 & 27 & 64 \\
\hline
\end{tabular}

Fonte: Dados da pesquisa (2012).

A Tabela 3 agrupa os filhos e filhas dos produtores, de acordo com sua principal ocupação, relacionando o total de filhos que se enquadra em cada grupo e sua idade média.

Destaca-se que foram registrados somente aqueles que ainda estão morando na propriedade (totalizando 80), sendo que 21 filhos(as) têm a agricultura como principal ocupação, enquanto um número mais elevado (46) é de estudantes.

Tabela 3 - Idade dos filhos segundo sua ocupação

\begin{tabular}{lccccc}
\hline Ocupação & Total & Média & Desvio Padrão & Mínima & Máxima \\
\hline Geral & 80 & 16,10 & 8,47 & 1 & 39 \\
Outro & 8 & 5,88 & 9,80 & 1 & 30 \\
Estudante & 46 & 12,93 & 4,57 & 4 & 23 \\
Agricultor & 21 & 24,05 & 6,76 & 14 & 39 \\
Trabalhador & 5 & 28,20 & 3,33 & 25 & 33 \\
\hline
\end{tabular}

Fonte: Dados da pesquisa (2012).

A 1, apresentada na próxima página, mostra um gráfico de frequência da escolaridade dos produtores, ressaltando que a maioria (66\%, i.e., 35 produtores) não completou o ensino fundamental, indicando que a amostra possui um baixo nível de instrução formal, o que pode dar pistas para explicar o baixo resultado obtido em relação ao grau de leitura (tanto em termos gerais quanto àquelas voltadas à atividade), conforme será demonstrado na Tabela 3.

A segunda maior frequência de escolaridade é entre os agricultores que concluíram apenas o ensino fundamental completo, seguida pelos que concluíram o ensino médio completo. 
Figura 1 - Gráfico de escolaridade dos produtores

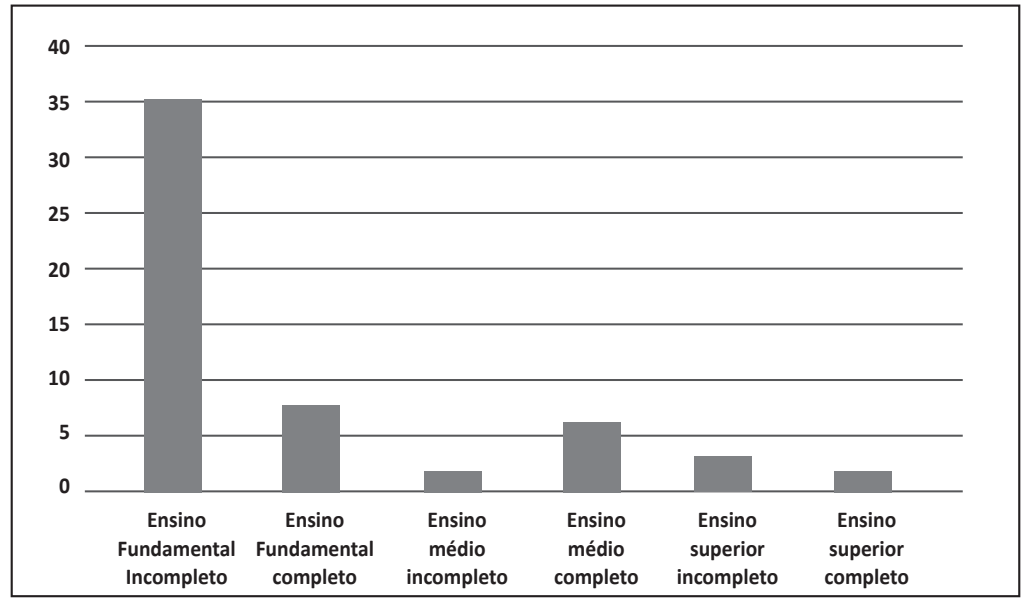

Fonte: Dados da pesquisa (2012).

A Tabela 4 apresenta informações a respeito das variáveis quantidade e intensidade de leitura em geral e para assuntos relacionados à atividade produtiva (agricultura). As questões foram organizadas utilizando uma escala do tipo Likert (na qual 1 significa muito baixa, e 5, muito alta). Como se pode observar, as respostas concentram-se nos extratos mais baixos. Nesse sentido, $41,5 \%$ dos entrevistados têm um hábito de ler entre baixo e muito baixo. Essa situação se acentua quando se designa a leitura com foco na ocupação produtiva dos entrevistados, estando, em média, $62,3 \%$ entre baixa e muito baixa.

Tabela 4 - Relação dos produtores com a leitura

\begin{tabular}{lcccc}
\hline & $\begin{array}{c}\text { Quantidade/intensidade de } \\
\text { leitura (geral) }\end{array}$ & \multicolumn{2}{c}{$\begin{array}{c}\text { Quantidade/intensidade de } \\
\text { leitura dirigida à sua atividade }\end{array}$} \\
\hline Muito baixa & $\mathrm{N}^{\circ}$ & $\%$ & $\mathrm{~N}^{\circ}$ & $\%$ \\
Baixa & 5 & 9,4 & 9 & 17,0 \\
Média & 17 & 32,1 & 24 & 45,3 \\
Alta & 20 & 37,7 & 16 & 30,2 \\
Muito alta & 9 & 17,0 & 3 & 5,7 \\
Média & 2 & 3,8 & 1 & 1,9 \\
Desvio Padrão & 2,74 & & 2,3 & \\
\hline
\end{tabular}

Fonte: Dados da pesquisa (2012).

Na Tabela 5, em média, observa-se que $73,5 \%$ dos produtores têm mais de 25 anos de experiência como agricultor. No caso específico do cultivo da banana, mais de 70 \% têm 15 anos ou mais de experiência na produção desse cultivo, o que indica que se trata de um grupo conhecedor desse ambiente e com experiências anteriores e informações para subsidiar suas decisões. 
Tabela 5 - Experiência na ocupação

\begin{tabular}{lcc}
\hline Anos de experiência produção de banana & $\mathbf{N}^{\circ}$ & $\%$ \\
\hline Até 15 anos & 14 & 26,4 \\
$15-28$ anos & 13 & 24,5 \\
28 - 40 anos & 19 & 35,8 \\
Mais de 40 anos & 7 & 13,2 \\
Total & 53 & 100,0 \\
Anos de experiência como agricultor & $\mathbf{N}^{\circ}$ & $\%$ \\
Até 25 anos & 14 & 26,4 \\
25 - 36 anos & 13 & 24,5 \\
36 - 44 anos & 13 & 24,5 \\
Mais de 44 anos & 13 & 24,5 \\
\hline Total & 53 & 100,0 \\
\hline
\end{tabular}

Fonte: Dados da pesquisa (2012).

A Tabela 6 mostra as variáveis relacionadas à ocupação e à origem dos pais e também outro conjunto de dados relativos à origem da terra (propriedade) e ao tempo em que ela pertence ao núcleo familiar. Esse conjunto de informações caracteriza a força dos laços desses produtores com sua origem e ocupação. Observa-se que mais de $98 \%$ dos produtores têm pais agricultores, e $94,30 \%$ deles nasceram na mesma região (na maioria dos casos, na mesma propriedade), hoje ocupada pelos produtores. Pode-se notar que $66,04 \%$ dos agricultores têm uma parte de sua propriedade oriunda de heranças, as quais, em média, estão nas famílias há quase oitenta anos.

Tabela 6 - Características dos produtores e relação com sua situação fundiária

\begin{tabular}{llccrr}
\hline & Média & $\mathbf{N}^{\circ}$ & $\begin{array}{c}\text { Desvio } \\
\text { padrão }\end{array}$ & Mín. & Máx. \\
\hline Pais agricultores & $98,10 \%$ & 52 & & & \\
Pais agricultores na mesma região & $94,30 \%$ & 50 & & & \\
Terra obtida por herança & $30,20 \%$ & & 34,42 & 0 & 100 \\
Terra obtida por compra & $58,68 \%$ & 38,58 & 0 & 100 \\
Terra obtida por arrendamento & $23,09 \%$ & 23,08 & 0 & 100 \\
Agricultores com herança & $66,04 \%$ & & & & \\
Terra de herança - anos na família & $79,97 \%$ & & $22,82 \%$ & 30 & 150 \\
\hline
\end{tabular}

Fonte: Dados da pesquisa (2012). 
A Tabela 7 apresenta os resultados obtidos das variáveis que investigam a sucessão familiar. Um dado que chama atenção na amostra é o alto índice de sucessores e o alto nível de confiança em relação a se manter na atividade: $84,9 \%$ dos entrevistados desejam ter um sucessor, e $64,2 \%$ indicam efetivamente haver um sucessor. Talvez isso se explique pelo incentivo e apoio dos pais aos jovens. Destaca-se que, entre os que não têm sucessores, há casos em que os entrevistados têm filhos muito pequenos, ou não têm filhos ainda, de maneira que a situação da sucessão poderá mudar nos próximos anos.

Tabela 7 - Sucessão familiar

\begin{tabular}{ccccccc}
\hline & $\begin{array}{c}\text { Pretende ficar na } \\
\text { agricultura }\end{array}$ & \multicolumn{2}{c}{$\begin{array}{c}\text { Deseja ter } \\
\text { um sucessor }\end{array}$} & \multicolumn{2}{c}{ Existe um sucessor } \\
\hline & $N^{\circ}$ & $\%$ & $N^{\circ}$ & $\%$ & $N^{\circ}$ & $\%$ \\
Sim & 52 & 98,1 & 45 & 84,9 & 34 & 64,2 \\
Não & 1 & 1,9 & 6 & 11,3 & 19 & 35,8 \\
\hline
\end{tabular}

Fonte: Dados da pesquisa (2012).

Os dados da Tabela 7 também demonstram que 98,1\% dos entrevistados pretendem manter-se na atividade agrícola. Dessa forma, ressalta-se que a propriedade não é vista apenas como um espaço de reprodução, mas envolve múltiplos significados para além das relações de produção e mercantis, transparecendo, sobretudo, o seu "lugar", o seu "lar", no sentido de pertencimento, com expectativas de longo prazo. Essas tendências se reforçam, quando observadas as informações do gráfico presente na Figura 2, em que 52 agricultores, o equivalente a $98 \%$ da amostra, concentram suas decisões na família e na sua manutenção, em uma lógica de manter a coesão familiar e seus projetos.

Figura 2 - Gráfico de concentração das decisões

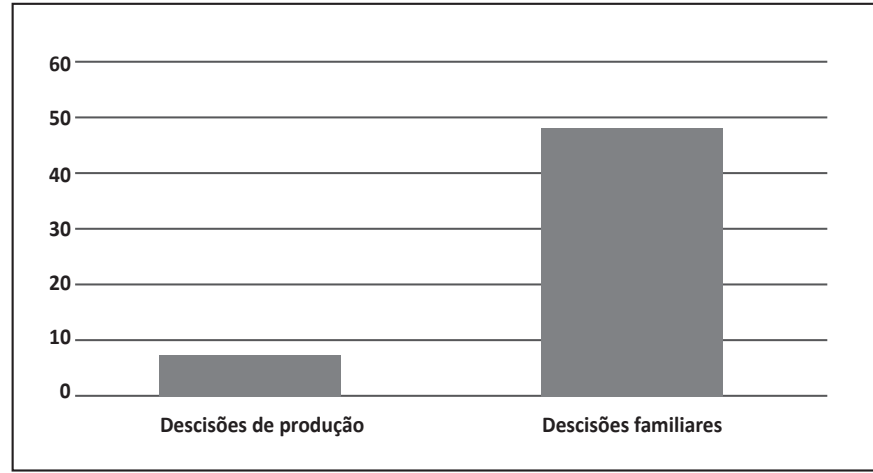

Fonte: Dados da pesquisa (2012).

A composição da renda das propriedades estudadas, com base nos dados do estudo de campo, demonstra que $67 \%$ das entradas financeiras têm origem na produção da banana. A análise do Produto Bruto $(P B)$ revela a concentração entre os estratos de 
vinte a sessenta mil reais por ano, os quais concentram $68 \%$ dos produtores, conforme Figura 3. No conjunto de valores mais baixos, até 20 mil reais anuais, encontram-se apenas $7 \%$ do total pesquisado, e no grupo de valores acima dos 60 mil reais, encontram-se $25 \%$ dos pesquisados. Esse indicador (PB) revela apenas a quantidade total produzida e comercializada pela unidade de produção. Os valores são anuais, e, portanto, o somatório do Produto Bruto, no primeiro caso (até $\mathrm{R} \$ 20$ mil), equivale a pouco mais de $\mathrm{R} \$ 1.500,00$ ao mês. Já no último (acima de $\mathrm{R} \$ 60.000,00$ ), o PB supera os $\mathrm{R} \$ 5.000,00$ mensais produzidos. Um diferencial dessas propriedades revela-se ao considerar que, mesmo tendo um PB considerado baixo, grande parte dele é destinado para o autoconsumo, o que tende a garantir autonomia da propriedade.

\section{Figura 3 - Gráfico de distribuição do Produto Bruto}

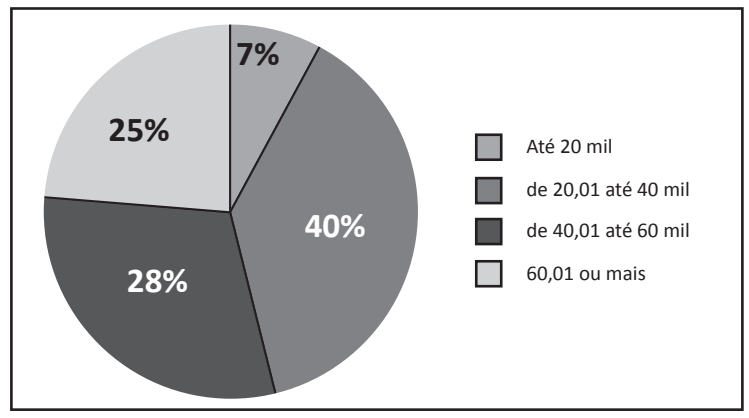

Fonte: Dados da pesquisa (2012).

A Tabela 8 mostra a força de trabalho disponível em cada propriedade. O UTH apresenta média de 1,03 e um desvio padrão de 0,6, ou seja, pode-se perceber que, na maioria dos casos, em torno de $68 \%$, existe $01 \mathrm{UTH}$. As propriedades com até duas unidades de UTH são $25 \%$ do total, e as que dispõem de dois até três unidades de UTH representam apenas $7 \%$ do total. Isso demonstra uma alta intensidade de trabalho, 0 qual, em geral, nessas propriedades, é todo manual.

\section{Tabela 8 - Medidas do UTH, ST, SAU, SAUB}

\begin{tabular}{lrrrr}
\hline & Média & $\begin{array}{r}\text { Desvio } \\
\text { Padrão }\end{array}$ & Min. & Max. \\
\hline UTH & 1,03 & 0,60 & 0,20 & 2,88 \\
ST - Área Total (ha) & 12,56 & 11,94 & 1,70 & 70,00 \\
SAU - Área útil (ha) & 7,95 & 8,26 & 1,40 & 55,00 \\
SAUB - Área útil destinada ao cultivo da banana (ha) & 4,62 & 7,06 & 0,30 & 52,00 \\
\hline
\end{tabular}

Fonte: Dados da pesquisa (2012).

A análise dos estratos de Superfície Agrícola Útil (SAU), na Tabela 7, demonstra que esses produtores dispõem de pequenos estratos de áreas agricultáveis, em geral com altos declives e limitações de mecanização. A Figura 4 revela que apenas $4 \%$ dos en- 
trevistados possuem dez ou mais hectares disponíveis para a produção. Os agricultores que dispõem de cinco até dez hectares são $17 \%$ do total, enquanto a maioria deles (79\%) possui até cinco hectares para produzir.

Esta última situação impõe limitações de escala aos agricultores e requer uma gestão estratégica, para que possam manter financeiramente as propriedades, considerando que sejam áreas pequenas com alto aporte de mão de obra. Mesmo tendo uma capacidade produtiva baixa, seja em termos de ST, SAU, UTH e PB, o grupo estudado tem sua reprodução social e econômica estabelecida, o que pode explicar o grande número de sucessores já estabelecidos.

\section{Figura 4 - Gráfico de valor de SAU}

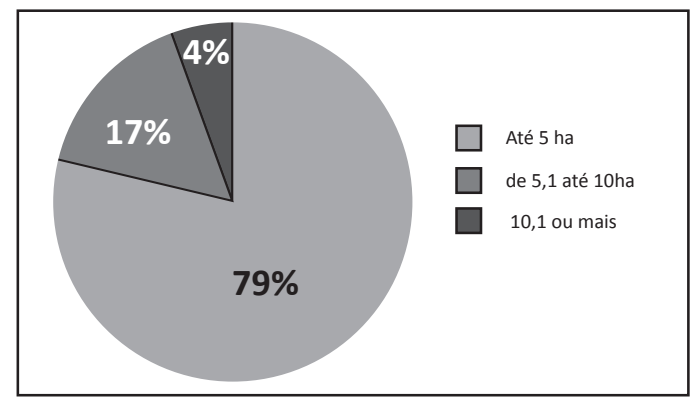

Fonte: Dados da pesquisa (2012).

Os arranjos que o agricultor desenvolve, para organizar o funcionamento da sua propriedade, passam, também, pela forma como ele se insere nos arranjos sociais locais e regionais. Essa inserção gera a possibilidade de espaços de trocas sociais. A participação de produtores em sindicados de classe, associações e cooperativas propicia, em geral, um espaço de reuniões e encontros para discutir, trocar e socializar experiências. Verificou-se que 48 entrevistados participam de associações ou cooperativas locais e 36 destes estão vinculados a uma entidade de representação de classe (Sindicato dos Trabalhadores Rurais).

Em relação ao Índice de Desenvolvimento Humano (IDH), esse indicador demonstra poucas diferenças entre as cidades. Torres é o município melhor qualificado, na comparação estadual entre todos os estudados, com 0,762. Em segundo lugar, aparece Três Cachoeiras, com IDH 0,718, seguido por Morrinhos do Sul $(0,711)$. Tais valores representam um IDH alto, enquanto os demais possuem um IDH médio, uma vez que o IDH de Dom Pedro de Alcântara é 0,691, e o de Mampituba é 0,649. É importante destacar que o estado do Rio Grande do Sul apresenta IDH 0,746, abaixo de Torres, mas acima de todos os outros municípios comparados neste trabalho.

Finalizando, é importante ressaltar que as análises das interações existentes entre os diferentes elementos que determinam a produção e o rendimento final são condicionadas à compreensão que a comunidade construiu, passando pelo entendimento da sinergia existente na organização de cada sistema de cultivo, bem como a relação estabelecida com critérios, como as condições ambientais (paisagem), população vegetal existente e a força de trabalho disponível. 
As condições paisagísticas observadas neste trabalho evidenciam indicativos que demonstram por que os sistemas de base ecológica se relacionam de forma mais harmoniosa com as potencialidades deste espaço. Os sistemas de cultivo convencionais aplicam, como uma forma de manejo, a limpeza total das áreas dos bananais, o que implica numa cobertura nula do solo. Logo, estes bananais estão mais suscetíveis a processos erosivos e a perda de fertilidade. Os sistemas de cultivo de base ecológica aplicam técnicas de manejo que priorizam a cobertura do solo por meio de roçadas (de controle) e da adubação verde, o que contribui para a ampliação e manutenção da fertilidade do solo, diminuindo a incidência de processos erosivos.

O manejo utilizado pelos sistemas de cultivo de base ecológica, na maioria dos casos, busca uma sinergia com a vegetação nativa em prol da espécie cultivada, além da sinergia com outros cultivos que compõem o sistema de produção (milho, feijão, aipim, hortaliças e frutíferas), o que não se observa nos sistemas de cultivo convencionais, onde a única espécie de vegetação tolerada na área de cultivo é a banana.

\section{Considerações finais}

Este artigo teve por objetivo analisar, além de indicadores sociais e econômicos, recursos e relações locais utilizados pelos agricultores produtores de banana da microrregião do Litoral Norte, no Rio Grande do Sul, que compõe o bioma da Mata Atlântica brasileira, para verificar os impactos das legislações ambientais sobre seus espaços.

Para tal, foram analisados indicadores, como o Índice de Desenvolvimento Humano (IDH), a superfície agrícola útil (SAU) e o produto bruto (PB), para verificar as transformações locais, decorrentes das restrições de uso do solo, impostas pela legislação ambiental.

As análises da amostra indicam que se trata de uma população com características de baixa instrução formal e com poucos hábitos de leitura. São famílias que têm suas origens na região e na agricultura e que, em grande parte, possuem mais de quinze anos de experiência na produção agrícola e no cultivo da banana. Um dos dados observados que chama a atenção é o elevado número de sucessores já estabelecidos. São propriedades, na sua grande maioria, com menos de dez hectares, com alta concentração de aporte de mão de obra e com uma capacidade produtiva baixa, como demonstraram os valores do Produto Bruto.

Este estudo evidenciou que os SAFs estão mais diretamente ligados às práticas locais, à cultura, à paisagem e aos seus recursos. Em suma, o que se abstrai é que estes demonstram características que podem ser potencializadas enquanto alternativas de desenvolvimento local e/ou endógeno de um território.

As considerações apresentadas no decorrer deste trabalho são particularmente relevantes em cenário atual, como no caso brasileiro, onde a agricultura passa, cada vez mais, a ser vista como um negócio, um empreendimento empresarial cuja gestão tem um caráter profissional, havendo uma crescente separação entre a produção e a ideia de família, que tem a terra apenas como um fator de produção, e não um modo de vida no sentido de pertencimento, sem perder de vista que tais relações estão interligadas aos seus objetivos, no intuito de projetar as ações presentes e futuras, as quais, neste 
caso observado, relacionam-se a sua permanência na agricultora e na expectativa da sucessão.

O que se evidenciou durante este trabalho foi a capacidade da comunidade de auto-organização, adequação diante dos embates e conflitos, bem como sua capacidade de reação a mudanças. Mas, sobretudo, a capacidade de absorver tais mudanças, reelaborando, a partir disso, seu modo de vida cotidiano, mantendo as funções do sistema de produção, da sociedade e do ambiente.

Diante do contexto demonstrado neste artigo, entende-se que a resiliência da comunidade analisada está associada aos Sistemas Agroflorestais (SAF), que permite a produção agrícola com a conservação de uso sustentável das florestas. Assim, o SAF vem configurando-se, na resposta de quase 500 agricultores, cuja principal produção é a banana, ao permitir o uso da terra e melhorar a renda dos produtores. O SAF, ainda, altera a geografia da produção, proporciona uma reorganização total dos arranjos produtivos e sociais e gera uma ressignificação dessa comunidade e do local.

\section{Referências}

BRASIL. Código do Meio Ambiente: Lei Federal no 9.605, de 12 de fevereiro de 1998 e Lei Estadual no 11.520, de 03 de agosto de 2000. 6. ed. Porto Alegre: CORAG, 2009a.

. Constituição Federal. Coletânea de Legislação Ambiental. Organização Odete Medauar. São Paulo: Revista dos Tribunais, 2009b.

PEROTTO, M. A. Influência da legislação ambiental no uso e conservação da bacia hidrográfica do rio Maquiné (RS), no período de 1964 a 2004. 2007. 148 f. Dissertação (Mestrado em Geografia) - Centro de Filosofia e Ciências Humanas. Universidade Federal de Santa Catarina, Florianópolis, 2007.

PNUD. Atlas do Desenvolvimento Humano no Brasil. Disponível em: <http://www.pnud. org.br/IDH/Atlas2013.aspx?indiceAccordion=1\&li=li_Atlas2013>. Acesso em: 13 ago. 2013.

SORIA, H. B. E.; BLANDTT, L. S.; RIBEIRO, J. P. Resiliência: a capacidade de adaptação e/ou transformação nas desigualdades sociais. In: III Jornada Internacional de políticas públicas questão social e desenvolvimento no século XXI. Maranhão, 2007.

WIVES, D. G. Funcionamento e performance dos sistemas de produção da banana na Microrregião do Litoral Norte do Rio Grande do Sul. 2008. 164f. Dissertação (Mestrado em Desenvolvimento Rural) - Curso de Pós-Graduação em Desenvolvimento Rural, Universidade Federal do Rio Grande do Sul, Porto Alegre, 2008. 